\title{
Effect of Flavoures on Cultures, Sugar Levels and Storage Periods of Shrikhand
}

\author{
Shiv Sharan ${ }^{1 *}$, M. P. S. Yadav ${ }^{1}$, Hari Shanker ${ }^{1}$, S. K. Shahi ${ }^{2}$ and Devendra Singh ${ }^{3}$ \\ ${ }^{1}$ Department of Animal Husbandry and Dairying, ${ }^{3}$ Department of Entomology, C. S. Azad \\ University of Agriculture and Technology, Knapur (U.P.), India \\ ${ }^{2}$ Animal Husbandry and Dairying, U.P. College (Autonomous) Bhojubir, \\ Varanasi (U.P.), India \\ *Corresponding author
}

\section{Keywords}

Cultures, Sugar

Levels and Storage

Periods of

Shrikhand

\section{Article Info}

\section{Accepted:}

15 January 2020

Available Online:

10 February 2020

\section{A B S T R A C T}

An experiment was conducted to investigate the effect of flavors on sensory quality of Shrikhand at Department of Animal Husbandry and Dairying of Chandra Shekhar Azad University of Agriculture and Technology, Kanpur (U.P.) India. The results of the present investigation showed that the flavour registered highest score (5.65) on milk sample of $\mathrm{A}_{2}$ (Lactococcus cremoris) followed by $\mathrm{A}_{3}$ (Streptococus diacetilactis) with score (5.45). The best flavour score (5.648) was noted in case of Shrikhand prepared with $40 \%$ sugar $\left(\mathrm{B}_{2}\right)$ while, lowest score (5.24) in case of $45 \%$ sugar level $\left(\mathrm{B}_{3}\right)$. The highest score (5.638) obtained from mango flavour $\left(\mathrm{C}_{3}\right)$ followed by (5.45) orange flavour $\left(\mathrm{C}_{2}\right)$ While, the lowest flavour score (5.25) in no flavor added. It was observed that highest flavour score (7.80) was in fresh samples of Lactococcus lactis subsp. cremoris $\left(\mathrm{A}_{2} \mathrm{D}_{1}\right)$; the next maximum flavour score (7.60) was in case of $\left(\mathrm{A}_{3} \mathrm{D}_{1}\right)$, While minimum flavour score (3.40) was noted in $\left(\mathrm{A}_{1} \mathrm{D}_{4}\right)$ samples. The maximum flavour score (5.84) was estimated in case of sample prepared with $40 \%$ sugar level and mango flavour $\left(\mathrm{B}_{2} \mathrm{C}_{3}\right)$ followed by $\left(\mathrm{B}_{2} \mathrm{C}_{2}\right)$ and $\left(\mathrm{B}_{1} \mathrm{C}_{3}\right)$, whereas the minimum score (5.05) was obtained from $45 \%$ sugar level without flavouring agent $\left(\mathrm{B}_{3} \mathrm{C}_{1}\right)$.

\section{Introduction}

Milk is an extremely complex biological fluid with sources of nutrients. These nutrients exist in milk in three physical phases: a dilute emulsion, a colloidal dispersion and a solution. The emulsion can be broken by low speed centrifugation and the milk separates into lipids and aqueous phases or compartments, each with a characteristic composition. Milk production in India during the year 2018-19 was 187.7 million tonnes. (Anonymous, 2019) which is likely to expand by 6.26 per cent. It is estimated that by 2020 , milk production would reach a level of over 200 million tonnes.

Shrikhand name is derived from Sanskrit word "Shikhrani" meaning good nourishing food having high protein, fat and calorific 
values and rich source of calcium, phosphorus, magnesium, potassium, zinc and vitamin $\mathrm{B}_{1}, \mathrm{~B}_{2}$ and $\mathrm{B}_{12}$. Typically Shrikhand constitutes 39.0 percent moisture and 61.0 percent of total solids of which 10.0 percent is fat, 11.5 percent proteins 78.0 percent carbohydrates and 0.5 percent ash, on a dry matter basis. It has a $\mathrm{pH}$ range of about 4.2 to 4.4 (Boghra and Mathur, 2000). According to Prajappati and Baboo, 2003, it originated in ancient Indian state Maharashtra, around 400 B.C.E. According to Bureau of Indian Standard (BIS) and under the Prevention of Food Adulteration (PFA) rule, Shrikhand is a delicious and delightful dessert of western India. It is made with chakka (strained dahi /curd) which is finely mixed with sugar, flavouring agents milk fat. It may contain fruits, nuts, sugar, cardamom, saffron and other spices. Dahi has the nutritive goodness of fermented milk products. It is very refreshing particularly during summer months. It is popular because of its characteristics flavour (like-Mango, Banana, orange, Saffron, Cardamom etc.), taste, palatable nature and possible therapeutic value. It is loaded with calcium and is good for the bones, assists in regulating cholesterol levels, helps in reducing high blood pressure, assists in digestion and prevents heartburn, reduces the risk of colorectal cancers and helps in weight loss.

Shrikhand is a popular Indian dessert prepared by the fermentation of buffalo milk. It has semi-soft consistency and has a sweet and sour taste.

Yoghurt is valued for controlling the growth of bacteria and incurring intestinal diseases like constipation, diarrhoea and dysentery (Shahani and Chandan, 1979). It has higher shelf life than milk and curd. Yoghurt is effective in lowering the blood cholesterol (Mana and Spoerry, 1974). On an industrial scale Shrikhand is prepared by using different mechanical devices (Aneja et al., 1977). In this process, pasteurized milk or skim milk is inoculated with the culture. The dairy based product is helpful to keep you full longer. It also aids in providing you with a better sleep. As shrikhand is served cool, it may also cool your body during summers. If you are wanting to gain weight, then this product can surely help. It helps your skin to gain softness and smoothness, nourishsing and gives you a supple and glowing skin and exfoliate your skin. This byproduct of milk helps to keep your hair nourished and removes dandruff from your scalp.

\section{Materials and Methods}

The present investigation was carried out in the Department of Animal Husbandry and Dairying of C.S.A. University of Agriculture and Technology, Kanpur (U.P.) India.

The details of materials and methods used for preparation of Shrikhand.

\section{Milk}

Take fresh buffalo milk (6\% fat and 9\% SNF).

Starter culture (used during preparing of Shrikhand):

Streptococus lactics., Streptococus cremoris and Streptococus diacetilactis.

\section{Sugar}

Commercial grade white crystalline sugar free from impurities.

\section{Colour and flavour}

NO colours added and three type of flavours without colours, orange, mango and checked (No flavour). 


\section{Packing materials}

Plastic cup was used for packaging.

\section{Methodology}

For preparing the Shrikhand buffalo milk was used and received from Department of Animal Husbandry and Dairying of Chandra Shekhar Azad University of Agriculture and Technology, Kanpur. Different cultures with flavoures and sugar were added for preparing Shrikhand.

\section{Flow chart for Shrikhand preparation}

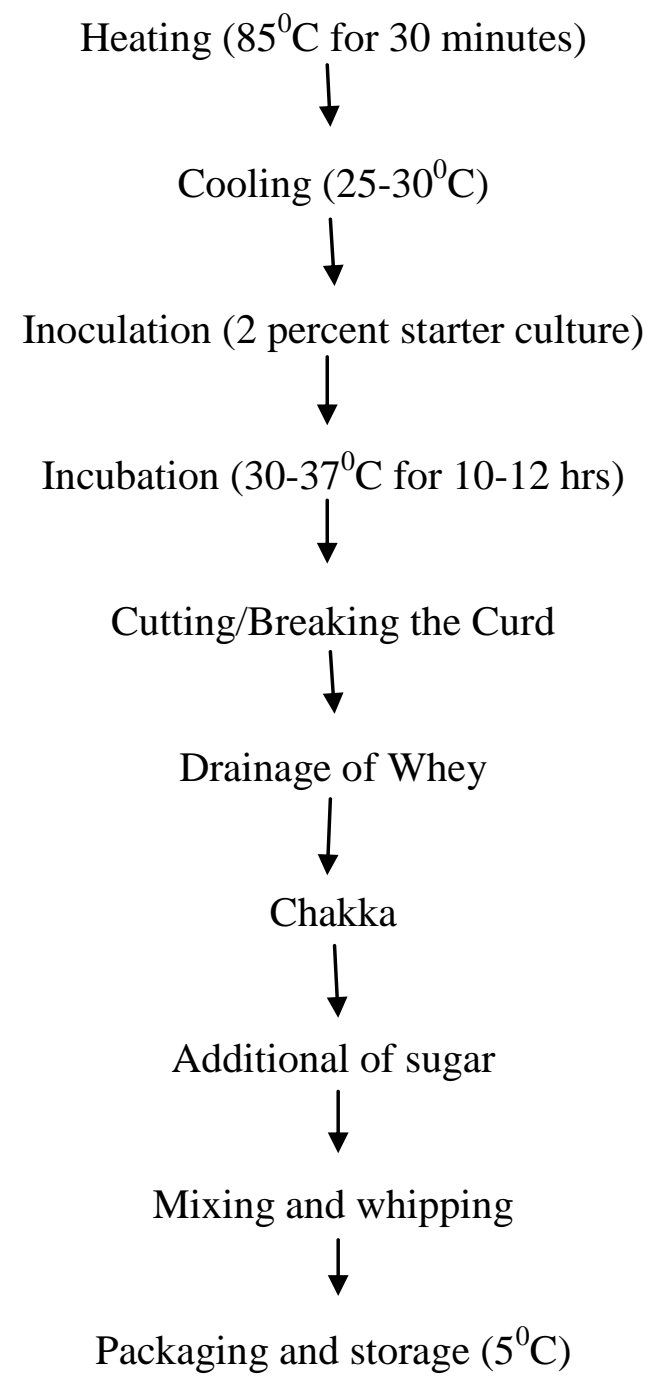

\section{Results and Discussion}

The results of present study as well as relevant discussion have been presented here:

In order to study the effect of different factors like different types of starter cultures (streptococcus lactis sub.sp.lactis, lacococcus lactis sub. Crimoris, Streptococcus diacetelactis) (A) with three sugar levels (35\%, 40, and 45\%) (B), three flavours (No flavoure, Orange and Mango) (C) and four storage periods (0day, 7 days, 14days and 21days) (D) on Shrikhand with respect to (1) Sensory evaluation (Flavoure, colour and appearance, Body and texture, Sweetness, and Overall acceptability) The laboratory experiment on variance of these data was worked out on the basis of factorial experiment in completely randomized design. The results drawn and their interpretations for different characters have been discussed systematically.

The flavour of Shrikhand is the most important quality attributes. A pleasant sweetish aroma and a mild clean acid taste are desirable characteristics of Shrikhand. A good pleasant diacetyle flavour is desired in Shrikhand. It should not show any signs of bitterness, saltiness as any other off flavour. The flavour of Shrikhand as affected by different factors have been presented in Table 1.

The highest score (5.65) of flavour was found in milk sample of $\mathrm{A}_{2}$ (Lactococcus cremoris) followed by $\mathrm{A}_{3}$ (Streptococus diacetilactis) score (5.45). The mean difference (0.030) in scores was recorded among $\mathrm{A}_{2}, \mathrm{~A}_{3}$ and $\mathrm{A}_{1}$, when compared with $\mathrm{CD}$ at $5 \%$ level. The flavour scores varied significantly from one another's.

On comparing average scores of flavour and aroma of Shrikhand in case of different types 
of sugar level. It was observed that the best flavour score (5.648) was noted in case of Shrikhand prepared with $40 \%$ sugar $\left(\mathrm{B}_{2}\right)$ and lowest score (5.24) in case of $45 \%$ sugar level $\left(\mathrm{B}_{3}\right)$. The present findings almost supports neck to neck with the findings of Singh et al., (2015).

Effect of flavouring agent (C) on flavour score of Shrikhand, it was observed that the highest score (5.638) obtained from mango flavour $\left(\mathrm{C}_{3}\right)$ followed by orange flavour $\left(\mathrm{C}_{2}\right)$. While, the lowest flavour score (5.25) observed from Shrikhand prepared without flavouring agent. $\left(\mathrm{C}_{1}\right)$.

As regard the storage periods, the maximum flavour score (7.60) of Shrikhand was noted in fresh samples while, minimum flavour score (3.60) was observed when samples stored at 21 days.

The findings of Patel et al., (1993) also supports the present findings, they reported that the chakka can be preserved for a period of 10-15 days at refrigeration temperature, after adding sweeteners can be stored for 3540 days at refrigeration temperature $5^{\circ} \mathrm{C}$.

From Table No. 1 denoting the mean interactions between type starter cultures (A) and Sugar levels (B), it was observed that Shrikhand prepared from Lactococcus lactis subsp. cremoris with $40 \%$ sugar $\left(\mathrm{A}_{2} \mathrm{~B}_{2}\right)$ showed maximum score (5.85), followed by $\left(\mathrm{A}_{2} \mathrm{~B}_{1}\right)$ and $\left(\mathrm{A}_{3} \mathrm{~B}_{2}\right)$ with the same flavours score (5.65), while minimum flavour score (5.02) observed from $\left(A_{1} B_{3}\right)$ samples.

Among the blend treatment combinations of type of starter cultures (A) and flavouring agents $(\mathrm{C})$, the maximum flavour score (5.85) observed from Lactococcus lactis subsp. cremoris with mango flavour $\left(\mathrm{A}_{2} \mathrm{C}_{3}\right)$ followed by $\mathrm{A}_{2} \mathrm{C}_{3}$ (5.65) and $\mathrm{A}_{3} \mathrm{C}_{3}$ (5.65) scores, while minimum flavour score (5.05) observed from $\left(\mathrm{A}_{1} \mathrm{C}_{1}\right)$.

From the interaction A.D, it was observed that highest flavour score (7.80) was in fresh samples of Lactococcus lactis subsp. cremoris $\left(\mathrm{A}_{2} \mathrm{D}_{1}\right)$. The next maximum flavour score (7.60) was in case of $\left(\mathrm{A}_{3} \mathrm{D}_{1}\right)$. While minimum flavour score (3.40) was noted in $\left(\mathrm{A}_{1} \mathrm{D}_{4}\right)$ samples.

Among the treatment combination of sugar levels and flavouring agents (B and $\mathrm{C}$ ), it was observed that maximum flavour score (5.84) was estimated in case of sample prepared with $40 \%$ sugar level and mango flavour $\left(\mathrm{B}_{2} \mathrm{C}_{3}\right)$ followed by $\left(\mathrm{B}_{2} \mathrm{C} 2\right)$ and $\left(\mathrm{B}_{1} \mathrm{C}_{3}\right)$, whereas the minimum score (5.05) was obtained from 45 $\%$ sugar level without flavouring agent $\left(\mathrm{B}_{3} \mathrm{C}_{1}\right)$.

Table.1 Effect of flavoures on cultures, sugar levels and storage periods of Shrikhand

\begin{tabular}{|l|l|l|l|l|l|l|l|l|l|l|l|}
\hline Treatments & B1 & B2 & B3 & C1 & C2 & C3 & D1 & D2 & D3 & D4 & Mean \\
\hline A1 & 5.250 & 5.444 & 5.022 & 5.050 & 5.250 & 5.416 & 7.400 & 5.963 & 4.192 & 3.400 & 5.238 \\
\hline A2 & 5.650 & 5.850 & 5.450 & 5.450 & 5.650 & 5.850 & 7.800 & 6.400 & 4.600 & 3.800 & 5.650 \\
\hline A3 & 5.450 & 5.650 & 5.250 & 5.250 & 5.450 & 5.650 & 7.600 & 6.200 & 4.400 & 3.600 & 5.450 \\
\hline B1 & & & & 5.250 & 5.450 & 5.650 & 7.600 & 6.200 & 4.400 & 3.600 & 5.450 \\
\hline B2 & & & & 5.450 & 5.650 & 5.844 & 7.800 & 6.400 & 4.592 & 3.800 & 5.648 \\
\hline B3 & & & & 5.050 & 5.250 & 5.422 & 7.400 & 5.963 & 4.200 & 3.400 & 5.240 \\
\hline C1 & & & & & & & 7.400 & 6.000 & 4.200 & 3.400 & 5.250 \\
\hline C2 & & & & & & & 7.600 & 6.200 & 4.400 & 3.600 & 5.450 \\
\hline C3 & & & & & & & 7.800 & 6.363 & 4.592 & 3.800 & 5.638 \\
\hline Mean & 5.450 & 5.648 & 5.240 & 5.250 & 5.450 & 4.697 & 7.600 & 6.187 & 4.397 & 3.600 & 5.446 \\
\hline
\end{tabular}


Table.2 Analysis of variance for flavour of Shrikhand

\begin{tabular}{|l|l|l|l|l|l|}
\hline S.V & df & S.S & MSS & F. Ratio \\
\hline A & 2 & 9.1279 & 4.5640 & 364.0375 & $* * *$ \\
\hline B & 2 & 8.9648 & 4.4824 & 357.5334 & $* * *$ \\
\hline C & 2 & 8.1680 & 4.00840 & 325.7526 & $* * *$ \\
\hline D & 3 & 785.4375 & 261.8125 & 20883.0640 & $* * *$ \\
\hline AxB & 4 & 0.0107 & 0.0027 & 0.2142 & N.S \\
\hline AxC & 4 & 0.0186 & 0.0046 & 0.3700 & N.S \\
\hline AxD & 6 & 0.0195 & 0.0033 & 0.2596 & N.S \\
\hline BxC & 4 & 0.0107 & 0.0027 & 0.2142 & N.S \\
\hline BxD & 6 & 0.0205 & 0.0034 & 0.2726 & N.S \\
\hline CxD & 6 & 0.0176 & 0.0029 & 0.2337 & N.S \\
\hline AxBxC & 8 & 0.0586 & 0.0073 & 0.5842 & N.S \\
\hline AxBxD & 12 & 0.0898 & 0.0075 & 0.5972 & N.S \\
\hline AxCxD & 12 & 0.0869 & 0.0072 & 0.5777 & N.S \\
\hline BxCxD & 12 & 0.0908 & 0.0076 & 0.6037 & N.S \\
\hline AxBxCxD & 24 & 0.3145 & 0.0131 & 1.0451 & \\
\hline Error & 216 & 2.7080 & 0.0125 & Error & \\
\hline Total & 323 & 815.1553 & & & \\
\hline
\end{tabular}

Fig.1 Effect of flavoures on cultures, sugar levels and storage periods of Shrikhand

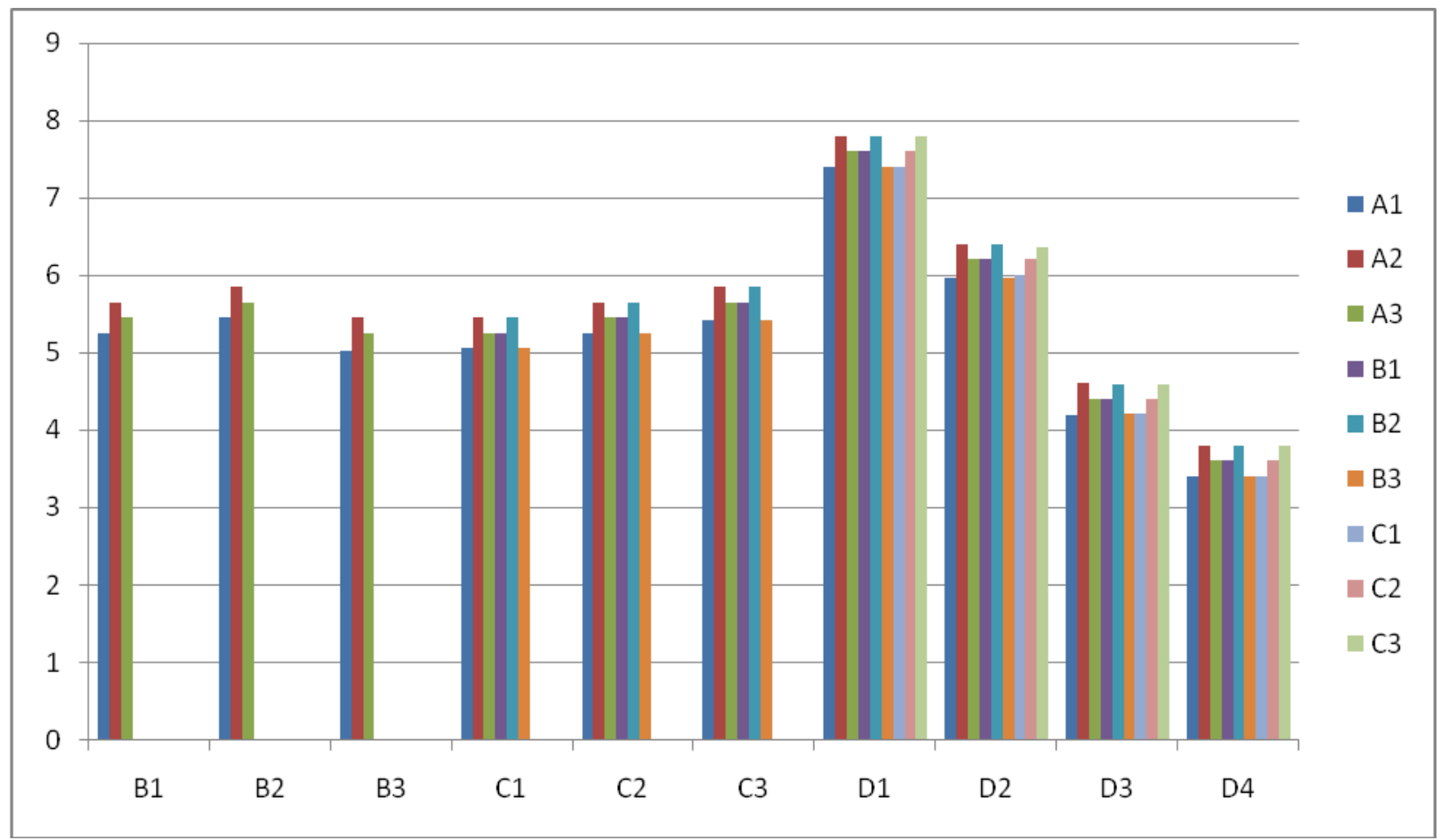

From the mean interactions of B and D, it was investigated that the highest flavour score (7.80) was noted in fresh samples of $40 \%$ sugar levels $\left(\mathrm{B}_{2} \mathrm{D}_{1}\right)$ followed by $\mathrm{B}_{1} \mathrm{D}_{1}$, while minimum flavour score (3.40) was obtained from $\left(\mathrm{B}_{3} \mathrm{D}_{4}\right)$ samples. 
From interactions $\mathrm{C}$ and $\mathrm{D}$, it was found that the maximum flavour score (7.80) of Shrikhand was in case of fresh sample prepared with mango flavour $\left(\mathrm{C}_{3} \mathrm{D}_{1}\right)$ followed by $\mathrm{C}_{2} \mathrm{D}_{1}$ with score of (7.60) and minimum score (3.40) was noted in $\mathrm{C}_{1} \mathrm{D}_{4}$ samples.

From Table no. 1 the effect of types of starter cultures, sugar levels, flavouring agents and storage periods (A, B, C and D) on flavour score of Shrikhand. It was observed that the maximum score (8.20) was registered from fresh samples prepared from the combination of Lactococcus lactis subsp. cremoris with 40 $\%$ sugar level and mango flvour $\left(\mathrm{A}_{2} \mathrm{~B}_{2} \mathrm{C}_{3} \mathrm{D}_{1}\right)$ followed by the combination of $\mathrm{A}_{2} \mathrm{~B}_{2} \mathrm{C}_{2} \mathrm{D}_{1}$, $\mathrm{A}_{2} \mathrm{~B}_{1} \mathrm{C}_{3} \mathrm{D}_{1}, \quad \mathrm{~A}_{3} \mathrm{~B}_{2} \mathrm{C}_{3} \mathrm{D}_{1}, \quad \mathrm{~A}_{3} \mathrm{~B}_{1} \mathrm{C}_{3} \mathrm{D}_{1} \quad$ and $\mathrm{A}_{2} \mathrm{~B}_{3} \mathrm{C}_{3} \mathrm{D}_{1}$ which were statistically at par with respect to flavour of Shrikhand and were graded excellent quality and liked extremely. The lowest score (3.00) was obtained from $\mathrm{A}_{1} \mathrm{~B}_{3} \mathrm{C}_{1} \mathrm{D}_{4}$ samples and were graded as poor quality.

The analysis of variance Table No.-2 for flavour scores of Shrikhand, it was revealed that the main effect of factors A, B, C and D was registered to be highly significant and the rest all first, second and third order interactions were observed to be nonsignificant.

\section{Acknowledgement}

The author thanks the Head, Department of Animal Husbandry and Dairying, to provide essential material and equipment for conducting an experiment in Laboratory,
Diptt. of A. H. and Dairying of Chandra Shekhar Azad University of Agriculture and Technology Kanpur -208002 (U.P.) and for the necessary facilities that were made available to carry out the research work.

\section{References}

Aneja, V.; Nanda and Thareja (1977). Development of an industrial process for the manufacture of Shrikhand. Journal of Food Science Technology; 14:159-163.

Anonymous (2019). Basic Animal Husbandry Statistics, Department of Animal Husbandry, Dairying and Fisheries, Ministry of Agriculture, Govt. of India. Development.

Boghra, and Mathur, O.N. (2000). Physicochemical status of major milk constituents and minerals at various stages of shrikhand preparation. Journal of food science and Technology (Mysore); 37(2): 111-115.

Prajappati, J.B. and Nair, B. M. (2003). "The History of Fermented Foods". In Edward R. Farnworth (ed.). Handbook of Fermented Functional Foods. CRC Press. pp. 4-6.

Mann, G.G. and Spoerry, A. (1974). AmJ.Clin Nutr; 27:464.

Shahani, K.M. and Chandan, R.C. (1979). Journal of Dairy Science; 62:1685.

Singh, M.; Gupta, R.; Andhare, B. C. and Singh, S. (2015). Effect of fat and sugar on sensory quality of Shrikhand. Research Journal of Animal Husbandry and Dairy Science; 6(1):52-56.

\section{How to cite this article:}

Shiv Sharan, M. P. S. Yadav, Hari Shanker, S. K. Shahi and Devendra Singh. 2020. Effect of Flavoures on Cultures, Sugar Levels and Storage Periods of Shrikhand. Int.J.Curr.Microbiol.App.Sci. 9(02): 2313-2318. doi: https://doi.org/10.20546/ijcmas.2020.902.262 